\title{
QUANTIFICATIONAL READINGS OF INDEFINITES WITH FOCUSED CREATION VERBS
}

\author{
Tamina Stephenson, \\ Massachusetts Institute of Technology \\ tamina@mit.edu
}

\begin{abstract}
This paper looks at sentences with "quantificational indefinites," discussed by Diesing (1992) and others. I propose that these sentences generate sets of alternatives of the form $\{p$, not $p$ and it's possible that $\mathrm{p}$ \}, which restrict the quantification by an extension of familiar focus principles. For example, in the sentence I usually read a book about slugs (on the relevant reading), usually quantifies over pairs $\langle\mathrm{x}, \mathrm{t}\rangle$ such that $\mathrm{x}$ is a book about slugs, $\mathrm{t}$ is a time interval, and one alternative is true from the set $\{\mathrm{I}$ read $\mathrm{x}$ at $\mathrm{t}, \mathrm{I}$ can but do not read $\mathrm{x}$ at $\mathrm{t}\}$. In addition to accounting for a wellknown contrast between creation and non-creation verbs, this also explains a second contrast that Diesing's analysis cannot account for.
\end{abstract}

\section{1 “Quantificational” Readings of Indefinites}

\subsection{The relevant reading}

The central data for this paper involves the availability or unavailability of a certain reading of indefinite objects in English sentences. This kind of reading comes up in sentences with adverbial quantifiers such as usually, and can be brought out most clearly in examples like (1).

(1) I usually love a sonata by Dittersdorf.

[Diesing (1992): 113]

The salient reading of (1) is, roughly, that in most cases when I hear a sonata by Dittersdorf, I love it. I'll follow Diesing (1992) and others in referring to this kind of reading of an indefinite object as a "quantificational" reading. The key property of this reading is that the adverb seems to be quantifying (in some sense) over individuals that satisfy the description in the indefinite. For example, in (1), usually is quantifying in some sense over sonatas by Dittersdorf.

\subsection{First contrast: creation vs. non-creation verbs}

Diesing observes that a quantificational reading is possible with verbs like read but not with creation verbs like write. That is, while (2) allows two readings, (3) only allows one.

(2) I usually read a book about slugs.

(i) $\approx$ [On Tuesdays] What I usually do is read a book about slugs.

(ii) $\approx$ When I encounter a book about slugs, I usually read it.

\footnotetext{
* I'd like to give special thanks to Irene Heim and Kai von Fintel for their extensive discussion and guidance. I'd also like to thank Marcelo Ferreira, Danny Fox, Sabine Iatridou, Polly Jacobson, Roger Schwarzschild, my classmates in the fall 2004 workshop course at MIT, the MIT Syntax/Semantics Reading Group, and the audience at Sinn und Bedeutung for useful comments and discussion.
} 
(3) I usually write a book about slugs.

(i) $\approx$ [In the summer] What I usually do is write a book about slugs.

(ii) $\neq$ When I encounter a book about slugs, I usually write it

/ I'm usually the one who wrote it

I will assume, following Diesing and others, that the difference between the two readings has to do with whether the indefinite object serves as part of the first argument of the quantifier (the restrictor) or the second (the nuclear scope). In quantificational readings (ii), the indefinite somehow serves as the restrictor, with the rest of the clause serving as the nuclear scope. In existential readings (i), on the other hand, the restrictor comes from elsewhere (in some cases from context) and the whole clause is the nuclear scope.

\subsection{Diesing's approach: a preexistence requirement}

Diesing tries to account for the contrast in (2)-(3) by introducing a preexistence requirement on indefinites in restrictors. This in effect restricts the quantification in these sentences on the quantificational reading (but not the existential reading) to preexisting books about slugs, that is, books that exist before the reading or writing is done to them. With a verb like read, a quantificational reading is still allowed, because in any case it only makes sense to read books that are already written. With a creation verb like write, however, this renders the quantificational reading nonsensical, since it only makes sense to write books that aren't already written. This account correctly predicts that quantificational readings are impossible with creation verbs, and seems to have a fair amount of intuitive appeal; nevertheless I'll show that it's empirically inadequate.

\subsection{Problem for preexistence: FOCUSED creation verbs}

The problem with a preexistence approach is that it also rules out the sentences in (4), on the indicated readings. These have contrastive focus on a verb of creation. ${ }^{1}$

(a) I usually [HANDwrite $]_{\mathrm{FOC}}$ a book about slugs. $=$ When I write a book about slugs, I usually do it by hand.

(b) I usually [KNIT $]_{\mathrm{FOC}}$ a scarf. $=$ When I make a scarf, I usually do it by knitting.

For example, (4.b) clearly quantifies in some sense over a set of scarves, saying that I knit most of them (as opposed to, say, crocheting them). Since knit is a creation verb, the quantification must be over scarves that don't exist until after the knitting has occurred, which should be impossible on the preexistence view.

\subsection{Outline of paper}

This paper will be structured as follows: In Sections 2-3, I'll lay out some assumptions about adverbial quantifiers and quantificational indefinites. Then in Section 4 I'll show how sentences with focused creation verbs like (4) can be derived using independently motivated principles of focus and quantification. In Section 5, I'll extend these principles in a new way to apply to quantificational readings without contrastive focus, giving intuitively correct truth conditions for these sentences. In Sections 6-7, I'll show how this captures the original contrast between creation and non-creation verbs in sentences like (2)-(3).

\footnotetext{
${ }^{1}$ The focus literature contains many examples with focused verbs, of course, including some that happen to be creation verbs, but I haven't seen this particular issue about Diesing's predictions pointed out.
} 


\section{Preliminary Assumptions}

\subsection{Contribution of aspect}

One assumption I'll make is that tensed clauses always have either perfective or imperfective aspect. The aspect morphemes will be abbreviated PERF and IMPF, respectively, and their lexical entries are given in (5). ${ }^{2}$

(a) $\quad\left[P E R F \rrbracket=\left[\lambda \mathrm{f}_{\langle\mathrm{i}, \mathrm{t}\rangle} \cdot\left[\lambda \mathrm{t} . \exists \mathrm{t}^{\prime}\left[\mathrm{t}^{\prime} \subseteq\right.\right.\right.\right.$ int $\mathrm{t}$ and $\left.\left.\left.\mathrm{f}\left(\mathrm{t}^{\prime}\right)=1\right]\right]\right]$

(b) $\quad\left[\mathrm{IMPF} \rrbracket=\left[\lambda \mathrm{f}_{\langle\mathrm{i}, \mathrm{t}\rangle} \cdot\left[\lambda \mathrm{t} . \exists \mathrm{t}^{\prime}\left[\mathrm{t}^{\prime} \supseteq\right.\right.\right.\right.$ int $\mathrm{t}$ and $\left.\left.\left.\mathrm{f}\left(\mathrm{t}^{\prime}\right)=1\right]\right]\right]$

[where $\subseteq_{\text {int }}$ and $\supseteq_{\text {int }}$ represent the sub- and superinterval relations]

In effect, PERF takes a set of intervals and yields the set containing those intervals plus all of their superintervals; IMPF does the same thing except that it adds the subintervals. This is shown pictorially in (6).

\section{(6) Effect of perfective and imperfective aspect}

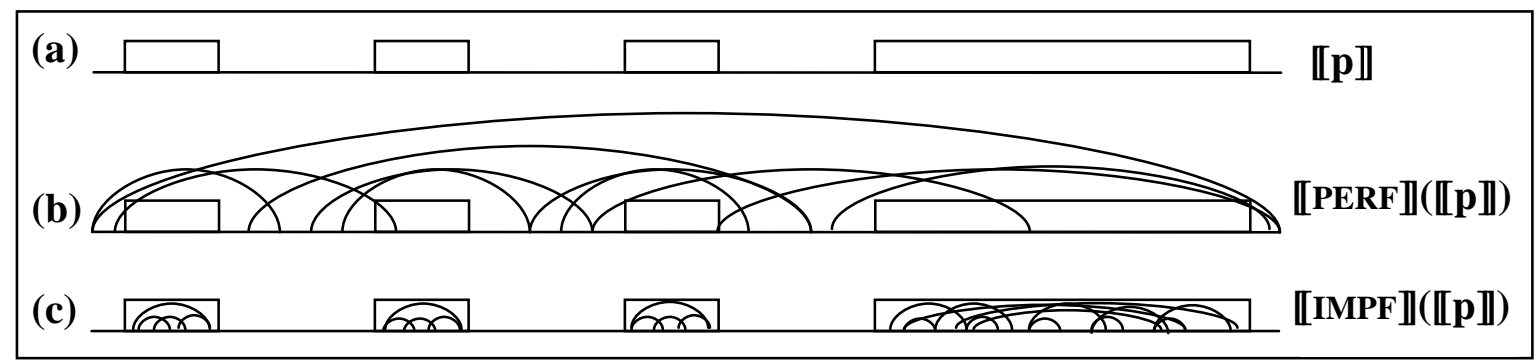

\subsection{Basic use of usually / always}

I assume that on its basic reading, usually is a quantifier over times, construed as intervals. For example, I analyze the sentences in (7) as having the truth conditions given in ( $7^{\prime}$ ). (I take the when-clause to have imperfective aspect and the main clause to have perfective aspect.)

(7) (a) When it's raining I usually call my mother.

(b) When it's raining I always call my mother.

(7') $\llbracket(a) /(b) \rrbracket=[$ Given some relevant time span $\mathrm{T}]$ for most/all intervals $\mathrm{t}$ such that $\mathrm{t} \subseteq_{\text {int }} \mathrm{T}$ AND $t$ is a maximal interval at which it's raining, there is some subinterval $t$ ' of $t$ such that I call my mother at $\mathrm{t}^{\prime}$.

$\approx$ during most /all periods of rain, I call my mother at some point

\subsection{Maximal intervals}

In (7') there's a reference to "maximal intervals" at which it's raining. ${ }^{3}$ This is important for the following reason: suppose that we counted all intervals of rain, that is, not only the intervals where it starts raining, rains for a while, and then stops, but the subintervals of those as well. Then we would be quantifying over a set of intervals that looked like (8.b).

\footnotetext{
2 I'm ignoring the "imperfective paradox" (see, e.g., Landman 1992, Portner 1998, and Parsons 1990).

${ }^{3}$ I'm assuming that when makes no truth conditional contribution. Johnston (1994) argues against this; but in any case the quantification has to somehow be restricted to maximal intervals in this kind of example.
} 


\section{(8) Intervals of rain}

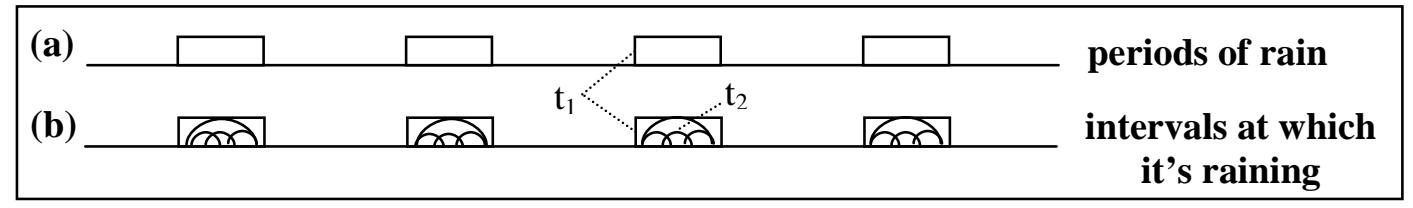

Now consider the intervals marked $t_{1}$ and $t_{2}$. For (7.b) to be true, for one thing I would have to call my mother at some subinterval of $t_{1}$. Then for another thing I would have to call my mother at some subinterval of $t_{2}$. When this is repeated for all the intervals illustrated in (8.b), the result is that I have to call my mother at multiple overlapping intervals - an infinite number of them, if we assume that time is dense. Intuitively, though, the sentence only requires that I call my mother once during each entire period of rain (when it starts, rains for a while, and then stops) - i.e., the intervals in (8.a).

\subsection{The first lexical entry for usually}

A lexical entry for the basic meaning of usually that will yield the truth conditions in (7') is given below in (9). Basic meanings for other temporal quantifiers such as always and rarely would be exactly parallel. I've included the "relevant time span" as a parameter. ${ }^{4}$

$$
\begin{aligned}
& \llbracket \text { usually }{ }_{1} \rrbracket^{\mathrm{T}}=\left[\lambda \mathrm{p}_{<\mathrm{i}, \mathrm{t}>} .\left[\lambda \mathrm{q}_{<\mathrm{i}, t>} . \text { For most times } \mathrm{t} \in \operatorname{Max}\left(\mathrm{T}^{\mathrm{p}} \cap \mathrm{p}_{\mathrm{s}}\right), \mathrm{q}(\mathrm{t})=1\right]\right] \\
& \left.=\left[\lambda \mathrm{p} .\left[\lambda \mathrm{q} \cdot \mid \operatorname{Max}\left(\mathrm{T}^{\mathrm{p}} \cap \mathrm{p}_{\mathrm{s}}\right) \cap \mathrm{q}_{\mathrm{s}}\right\} \mid \text { is a sufficiently large fraction of }\left|\operatorname{Max}\left(\mathrm{T}^{\mathrm{p}} \cap \mathrm{p}_{\mathrm{S}}\right)\right|\right]\right]
\end{aligned}
$$

The requirement that intervals be maximal is enforced in (9) using an operator Max, which is defined in (10).

(10) Definition of Max:

For any set of intervals $S, \operatorname{Max}(S)=\left\{t: t \in S\right.$ and $\sim \exists t^{\prime}\left[t \subset_{\text {int }} t^{\prime}\right.$ and $\left.t^{\prime} \in S\right\}$,

where $\subset_{\text {int }}$ is the proper subinterval relation

Informally, (9) says that, given a relevant time span T, usually takes two sets of intervals as arguments (where $\mathrm{p}_{\mathrm{S}}$ is the restrictor and $\mathrm{q}_{\mathrm{S}}$ is the nuclear scope); the resulting sentence is true just in case, counting only subintervals of $\mathrm{T}$, most of the members of $\mathrm{p}_{\mathrm{S}}$ that are maximal in the sense defined in (10) are also members of $\mathrm{q}_{\mathrm{s}}$.

\subsection{Example of an indefinite object with usually u $_{1}$ the existential reading}

To see how the lexical entry for usually in (9) works, consider (11.a) on its existential reading (i). Assuming that the interpreted structure is (11.b), the predicted meaning is as in (11.c). (I also assume that $\mathrm{T}^{*}$ stands for "these days" and the restriction on Tuesdays comes from context.)
(a)
I usually read a book about slugs.
reading (i) $\approx$ [On Tuesdays] What I usually do is read a book about slugs.

(b)

$$
\text { LF: }
$$

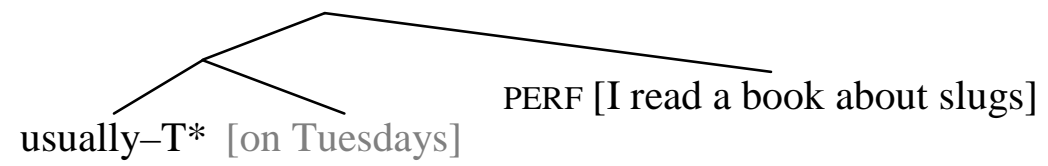

\footnotetext{
${ }^{4}$ For a function of type $\langle\alpha, t\rangle, f_{S}=$ the set characterized by $\mathrm{f}$ (though sometimes I'll use sets and their characteristic functions interchangeably). $\mathrm{T}^{\mathrm{p}}$ is the power set of $\mathrm{T}$, that is, the set of sets of points in time that are part of $\mathrm{T}$. This includes non-intervals, but intersecting this with $\mathrm{p}_{\mathrm{s}}$ will yield only intervals.
} 
(c) Meaning:

$\llbracket(11 . \mathrm{a}) \rrbracket=1$ iff for most maximal intervals $\mathrm{t}$ that are subintervals of $\mathrm{T}^{*}$ and are on Tuesday (i.e., entire Tuesdays within $\mathrm{T}^{*}$ ), there is some subinterval of $t$ at which I read a book about slugs.

There are two points to notice about (11). First, the perfective aspect (PERF) is crucial because without it the reading of each book would have to last all day. With the perfective aspect, a Tuesday only needs to be a superinterval of some time when I read a book about slugs to satisfy the quantification. Second, each Tuesday only counts once: for example, if I were to read four books about slugs some Tuesday, that wouldn't get me off the hook for the rest of the month.

\section{More Assumptions}

\subsection{Unselective binding}

I assume that adverbs like usually and always have a second lexical entry which is responsible for quantificational readings of indefinites. This second meaning is produced by extending the basic meaning in (9) to quantify over something other than just times. This is a version of the unselective binding approach to adverbial quantification (Lewis 1975). On this general view, there are various possibilities as to what the adverb could quantify over. Probably the simplest option is for it to quantify over individuals, but Percus (1999) shows that this is wrong. One crucial example he discusses is (12).

(12) [Context: Ursula is the subject of an experiment where blue-eyed bears walk in front of her one at a time, and she's supposed to judge whether each bear is intelligent.]

Ursula usually knew whether a blue-eyed bear was intelligent.

[Percus (1999): (17)]

If each bear only walked out once, then (12) would be equivalent to saying that for most of the bears, Ursula knew whether they were intelligent. That might lead us to think that the adverb is quantifying over individuals. But judgments change if we consider the possibility that a single bear could walk out more than once. In that case, it would be possible for Ursula to know for most bears whether they were intelligent and yet not know for most trials whether the bear in that trial was intelligent. (This would happen if the few bears whose intelligence she was unsure of came out many times while the many bears whose intelligence she was sure of came out few times.) Percus observes that in this kind of scenario, (12) is interpreted as quantifying over trials rather than bears. This means that the adverb can't be quantifying over individuals, and so I'll follow Percus in rejecting that analysis.

Given that the second meaning of adverbs can't quantify over individuals, I'll assume instead that it quantifies over pairs $\langle\mathrm{x}, \mathrm{t}\rangle$ of individuals and times. Again, this second meaning is an extension of the basic meaning in (9), which just quantifies over times. In (13) I give an example that will use this second lexical entry, deriving the meaning given in (13.b-c). The truth conditions given in (13) are only a first pass, though. In particular, at this point they turn out to be equivalent to quantifying over individuals, in effect ignoring the time part of the pairs; but this will change once other ingredients of the analysis are added in.

(13) (a) I usually / always love a sonata by Dittersdorf.

(b) $\quad=$ [Given a relevant time span $\mathrm{T}] 1$ iff for most / all pairs $\langle\mathrm{x}, \mathrm{t}\rangle$ such that $\mathrm{x}$ is a sonata by Dittersdorf and $\mathrm{t}$ is maximal, I love $\mathrm{x}$ at $\mathrm{t}$. 
(c) $\quad=[$ Given a relevant time span $\mathrm{T}] 1$ iff for most / all pairs $\langle\mathrm{x}, \mathrm{T}\rangle$

such that $\mathrm{x}$ is a sonata by Dittersdorf (where $\mathrm{T}$ is the entire relevant time span), I love $\mathrm{x}$ at $\mathrm{T}$.

$=1$ iff I love most /all sonatas by Dittersdorf within the relevant time span $\mathrm{T}$.

Again, the truth conditions given in (13.b-c) are only preliminary. Specifically, the step from (b) to (c) will become invalid once I adopt the crucial assumption in Section 5.

\subsection{A second lexical entry for usually}

A second lexical entry for usually that will yield the truth conditions in (13) is given in (14). Secondary meanings for other adverbs such as always and rarely would again be parallel.

(14) $\llbracket$ usually $\rrbracket_{2} \rrbracket^{T}=\left[\lambda P_{<e, i t>} .\left[\lambda Q_{<e, i t>}\right.\right.$. For most pairs $\left\langle x, t>\right.$ such that $t \in \operatorname{Max}\left(T^{p} \cap P(x)_{S}\right)$, $\mathrm{Q}(\mathrm{x})(\mathrm{t})=1]$ ], where Max is defined as in (10) above.

Informally, (14) says that, given a relevant time span T, usually takes two sets of pairs of individuals and times (where $\mathrm{P}_{\mathrm{S}}$ is the restrictor and $\mathrm{Q}_{\mathrm{S}}$ is the nuclear scope); the resulting sentence is true just in case, counting only subintervals of $T$, most of the members $\langle x, t\rangle$ of $P_{S}$ such that $t$ is maximal with respect to $x$ are also members of $Q_{s}$. To be a maximal member of $\mathrm{P}_{\mathrm{S}}$ "with respect to $\mathrm{x}$ " is just to be a maximal member of $\mathrm{P}(\mathrm{x})_{\mathrm{S}}$, which is to say maximality is defined separately for each individual $\mathrm{x}$ in the pairs $\langle\mathrm{x}, \mathrm{t}\rangle$.

\subsection{The restriction}

An additional assumption is needed to allow an indefinite object to be the restrictor argument of a quantifier. In particular, indefinites have to be able to denote sets of pairs of individuals and times. To accomplish this, I'll assume that an indefinite such as a book about slugs has the meaning shown in (15.a), corresponding to the meaning for the indefinite determiner $a$ in (15.b). This is in addition to its normal existential meaning, whether that involves existential quantification, choice functions, or something else. Of course it's a somewhat ad hoc move to give indefinites this secondary meaning, but anyone claiming that quantificational indefinites are part of the restrictor of quantifiers would need to make some assumption about how this comes about, and this is one way of doing that.

(a) $\llbracket \mathrm{a}_{2}$ book about slugs $\rrbracket=\left[\lambda \mathrm{x} .\left[\lambda \mathrm{t} . \exists \mathrm{t}^{\prime}[\mathrm{x}\right.\right.$ is a book about slugs at t'] $\left.]\right]$ $=\left\{\langle x, t\rangle: x\right.$ is a book about slugs at some time $\left.t^{\prime}\right\}$

(b) $\quad \llbracket \mathrm{a}_{2} \rrbracket=\left[\lambda \mathrm{P}_{\langle\mathrm{e}, \mathrm{it}\rangle} \cdot\left[\lambda \mathrm{x} \cdot\left[\lambda \mathrm{t} . \exists \mathrm{t}^{\prime}\left[\mathrm{P}(\mathrm{x})\left(\mathrm{t}^{\prime}\right)=1\right]\right]\right]\right]$

Informally, this says that a book about slugs, on its second meaning, denotes the set of pairs $<\mathrm{x}, \mathrm{t}\rangle$ such that $\mathrm{x}$ is a book about slugs and $\mathrm{t}$ is any time whatsoever.

An obvious question to ask is why the existential quantifier over times t' is introduced in (15). It would seem much more natural to say that a book about slugs simply denotes the set of pairs $\langle\mathrm{x}, \mathrm{t}\rangle$ such that $\mathrm{x}$ is a book about slugs at $t$. The reason I can't do this is that it would effectively reintroduce Diesing's preexistence requirement. (In fact, it would impose an even stronger requirement). We have already seen that this would incorrectly rule out sentences with focused creation verbs such as (4). 


\subsection{The nuclear scope}

Finally, I need to assume that the remaining part of the clause under usually - for example, I read - can be the nuclear scope. The meaning needed is given in (16). This can be achieved by movement of the indefinite object and abstraction over the trace, or some other means.

$$
\begin{aligned}
& {\left[\mathrm{I} \mathrm{read} \_\rrbracket=[\lambda \mathrm{x} .[\lambda \mathrm{t} . \mathrm{I} \operatorname{read} \mathrm{x} \text { at } \mathrm{t}]]\right.} \\
& =\{\langle\mathrm{x}, \mathrm{t}\rangle: \operatorname{Iread} \mathrm{x} \text { at } \mathrm{t}\}
\end{aligned}
$$

This just says that I read denotes the set of pairs $\langle\mathrm{x}, \mathrm{t}\rangle$ such that $\mathrm{I}$ read $\mathrm{x}$ at $\mathrm{t}$.

\subsection{Example of an indefinite object with usually: the quantificational reading}

With these assumptions in place, we can now see how a sentence with a quantificational indefinite is derived. I assume that (17.a) has the structure in (17.b), so the predicted meaning is as in (17.c-d).
(a)
I usually read a book about slugs.
$[=(2)]$

reading (ii) $\approx$ When I encounter a book about slugs, I usually read it.

(b) LF:

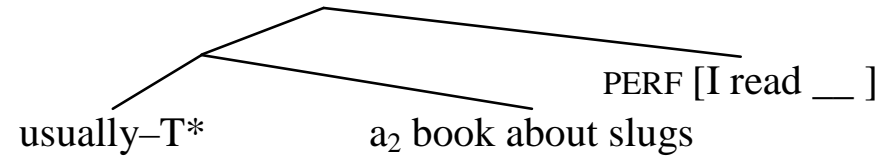

(c) Meaning:

$\llbracket(17 . a) \rrbracket=\llbracket$ usually $2 \rrbracket^{T^{*}}\left(\llbracket a_{2}\right.$ book about slugs $\left.\rrbracket\right)(\llbracket \operatorname{PERF}[$ I read _ $] \rrbracket)$ $=\llbracket$ usually $2 \rrbracket^{T^{*}}\left(\left[\lambda \mathrm{x} .\left[\lambda \mathrm{t} . \exists \mathrm{t}^{\prime}\left[\mathrm{x}\right.\right.\right.\right.$ is a book about slugs at $\left.\left.\left.\left.\mathrm{t}^{\prime}\right]\right]\right]\right)$

$\left(\left[\lambda \mathrm{x} .\left[\lambda \mathrm{t} . \exists \mathrm{t}^{\prime}\left[\mathrm{t}^{\prime} \subseteq\right.\right.\right.\right.$ int $\mathrm{t}$ and I read $\mathrm{x}$ at $\left.\left.\left.\mathrm{t}^{\prime}\right]\right]\right)$

$=1$ iff for most $\left\langle x, t>\right.$ such that $\mathrm{x}$ is a book about slugs at some $\mathrm{t}^{\prime}$, $\mathrm{t}$ is a subinterval of $\mathrm{T}^{*}$, and $\mathrm{t}$ is maximal (in the relevant sense), there is some subinterval of $t$ at which I read $x$.

(d) = 1 iff for most $\left\langle x, T^{*}\right\rangle$ such that $x$ is a book about slugs at some $t^{\prime}$, there is some subinterval of $\mathrm{T}^{*}$ at which I read $\mathrm{x}$.

$=1$ iff I read most books about slugs during $\mathrm{T}^{*}$.

Again, once the final parts of my analysis are added, the step from (c) to (d) will be invalid.

\section{Introducing Focus Sensitivity}

\subsection{The focus restriction}

It has been observed that focus plays a special role in restricting quantification (see, e.g., Rooth 1985 and von Fintel 1994). The principle in effect is roughly that in (18).

\section{(18) Focus restriction:}

Domains of quantification are restricted to cases where one focus alternative is true.

I'll make this clearer using an example. Consider the sentence in (19).

(19) John usually shaves [in the SHOWER $]_{\text {FOC. }}$

What (19) seems to mean is that usually when John shaves, he's in the shower. That is, the quantification is restricted to times when John shaves. Let's assume that the alternatives to in 
the shower are \{in the shower, at the sink \}. For simplicity, let's also assume that there are just seven relevant times, $t_{1}, t_{2}, \ldots t_{7}$. Now suppose the facts are as follows: John shaves in the shower at $t_{1}, t_{2}$, and $t_{3}$, and he shaves at the sink at $t_{4}$. He doesn't shave at all, either in the shower or at the sink, at $\mathrm{t}_{5}, \mathrm{t}_{6}$, or $\mathrm{t}_{7}$. Now we can construct the domain of quantification in steps. The first step is to give the set of alternatives for each of the relevant times $t_{1}-t_{7}$, as shown in (20).

(20) Step 1:

$\mathbf{t}_{1}: \quad\left\{\right.$ John shaves in the shower at $\mathrm{t}_{1}$, John shaves at the sink at $\left.\mathrm{t}_{1}\right\}$

$\mathbf{t}_{2}$ : $\quad$ John shaves in the shower at $\mathrm{t}_{2}$, John shaves at the sink at $\mathrm{t}_{2}$ \}

$\mathbf{t}_{3}$ : $\quad$ John shaves in the shower at $t_{3}$, John shaves at the sink at $t_{3}$ \}

$\mathbf{t}_{4}: \quad\left\{\right.$ John shaves in the shower at $\mathrm{t}_{4}$, John shaves at the sink at $\mathrm{t}_{4}$ \}

$\mathbf{t}_{5}: \quad\left\{\right.$ John shaves in the shower at $t_{5}$, John shaves at the sink at $t_{5}$ \}

$\mathbf{t}_{6}: \quad\left\{\right.$ John shaves in the shower at $\mathrm{t}_{6}$, John shaves at the sink at $\mathrm{t}_{6}$ \}

$\mathbf{t}_{7}: \quad\left\{\right.$ John shaves in the shower at $\mathrm{t}_{7}$, John shaves at the sink at $\left.\mathrm{t}_{7}\right\}$

The second step is to check, for each time $t_{i}$, whether either of the alternatives are true. Given the facts assumed above, the result is as in (21), where the true alternatives are in bold and underlined.

(21) Step 2:

$\mathbf{t}_{1}: \quad\left\{\right.$ John shaves in the shower at $\mathbf{t}_{1}$, John shaves at the sink at $\left.t_{1}\right\}$

$\mathbf{t}_{2}: \quad\left\{\right.$ John shaves in the shower at $\mathbf{t}_{2}$, John shaves at the sink at $t_{2}$ \}

$\mathbf{t}_{3}$ : $\quad$ John shaves in the shower at $\mathbf{t}_{3}$, John shaves at the sink at $t_{3}$ \}

$\mathbf{t}_{4}: \quad\left\{\right.$ John shaves in the shower at $t_{4}$, John shaves at the sink at $\left.\mathbf{t}_{4}\right\}$

$t_{5}:$ - John shaves in the shower at $t_{5}$, John shaves at the sink at $\left.t_{5}\right\}$

$t_{6}: \quad$ - John shaves in the shower at $t_{6}$, John shaves at the sink at $\left.t_{6}\right\}$

$t_{7}$ :- (John shaves in the shower at $t_{7}$, John shaves at the sink at $\left.t_{7}\right\}$

This is where the focus restriction from (18) comes in: since there's no true alternative for times $t_{5}, t_{6}$, or $t_{7}$, they are eliminated from the domain of quantification, leaving only $t_{1}, t_{2}, t_{3}$, and $t_{4}$. This means that three out of four cases satisfy the quantification, so sentence (19) is correctly predicted to be true in the context given. Notice that if all seven times were included in the domain, only three out of seven cases would satisfy the quantification and the sentence would be predicted to be false.

\subsection{Applying the focus restriction to quantificational indefinites}

Now let's see how the focus restriction applies in a more complicated case. Consider (22).

$$
\begin{aligned}
& \text { I usually }[\mathrm{KNIT}]_{\mathrm{FOC}} \text { a scarf. } \\
& \quad \approx \text { When I make a scarf, I usually do it by knitting. }
\end{aligned}
$$

Let's assume for simplicity that there are just four relevant scarves, $\mathrm{s}_{1}, \mathrm{~s}_{2}, \mathrm{~s}_{3}$, and $\mathrm{s}_{4}$, and four relevant times, $t_{1}, t_{2}, t_{3}$, and $t_{4}$ (where these times don't overlap). Let's also assume that the relevant alternatives to knit are $\{k n i t$, crochet, sew $\}$. Now suppose the facts are as follows: I knitted $s_{1}$ during $t_{1}, s_{2}$ during $t_{2}$, and $s_{3}$ during $t_{3}$; I sewed $s_{4}$ during $t_{4}$; and I didn't make any other relevant scarves during the relevant times. Again we can construct the domain of quantification in steps. The first step is to include all possible pairs of books and times and give the set of alternatives for each, as shown in (23).

(23) Step 1:

$$
\begin{array}{ll}
<\mathrm{s}_{1}, \mathrm{t}_{1}>: & \left\{\mathrm{I} \text { knit } \mathrm{s}_{1} \text { at } \mathrm{t}_{1}, \mathrm{I} \text { crochet } \mathrm{s}_{1} \text { at } \mathrm{t}_{1}, \mathrm{I} \text { sew } \mathrm{s}_{1} \text { at } \mathrm{t}_{1}\right\} \\
<\mathrm{s}_{\mathbf{1}}, \mathrm{t}_{\mathbf{2}}>: & \left\{\mathrm{I} \text { knit } \mathrm{s}_{1} \text { at } \mathrm{t}_{2}, \mathrm{I} \text { crochet } \mathrm{s}_{1} \text { at } \mathrm{t}_{2}, \mathrm{I} \text { sew } \mathrm{s}_{1} \text { at } \mathrm{t}_{2}\right\}
\end{array}
$$




\begin{tabular}{|c|c|}
\hline $\begin{array}{l}\left\langle\mathbf{s}_{1}, \mathbf{t}_{3}\right\rangle: \\
\left\langle\mathbf{s}_{1}, \mathbf{t}_{4}>:\right.\end{array}$ & $\begin{array}{l}\left\{I \text { knit } s_{1} \text { at } t_{3}, I \text { crochet } s_{1} \text { at } t_{3}, I \text { sew } s_{1} \text { at } t_{3}\right\} \\
\left\{I \text { knit } s_{1} \text { at } t_{4}, I \text { crochet } s_{1} \text { at } t_{4}, I \text { sew } s_{1} \text { at } t_{4}\right\}\end{array}$ \\
\hline $\begin{array}{l}\left\langle\mathbf{s}_{2}, \mathbf{t}_{1}\right\rangle: \\
\left\langle\mathbf{s}_{2}, \mathbf{t}_{2}\right\rangle: \\
\left\langle\mathbf{s}_{2}, \mathbf{t}_{3}\right\rangle: \\
\left\langle\mathbf{s}_{2}, \mathbf{t}_{4}\right\rangle:\end{array}$ & $\begin{array}{l}\left\{I \text { knit } s_{2} \text { at } t_{1}, I \text { crochet } s_{2} \text { at } t_{1}, I \text { sew } s_{2} \text { at } t_{1}\right\} \\
\left\{I \text { knit } s_{2} \text { at } t_{2}, I \text { crochet } s_{2} \text { at } t_{2}, I \text { sew } s_{2} \text { at } t_{2}\right\} \\
\left\{I \text { knit } s_{2} \text { at } t_{3}, I \text { crochet } s_{2} \text { at } t_{3}, I \text { sew } s_{2} \text { at } t_{3}\right\} \\
\left\{I \text { knit } s_{2} \text { at } t_{4}, I \text { crochet } s_{2} \text { at } t_{4}, I \text { sew } s_{2} \text { at } t_{4}\right\}\end{array}$ \\
\hline $\begin{array}{l}\left\langle\mathbf{s}_{3}, \mathbf{t}_{1}\right\rangle: \\
\left\langle\mathbf{s}_{3}, \mathbf{t}_{2}\right\rangle: \\
\left\langle\mathbf{s}_{3}, \mathbf{t}_{3}\right\rangle: \\
\left\langle\mathbf{s}_{3}, t_{4}\right\rangle:\end{array}$ & $\begin{array}{l}\left\{I \text { knit } s_{3} \text { at } t_{1}, I \text { crochet } s_{3} \text { at } t_{1}, I \text { sew } s_{3} \text { at } t_{1}\right\} \\
\left\{I \text { knit } s_{3} \text { at } t_{2}, I \text { crochet } s_{3} \text { at } t_{2}, I \text { sew } s_{3} \text { at } t_{2}\right\} \\
\left\{\text { I knit } s_{3} \text { at } t_{3}, I \text { crochet } s_{3} \text { at } t_{3}, I \text { sew } s_{3} \text { at } t_{3}\right\} \\
\left\{I \text { knit } s_{3} \text { at } t_{4}, I \text { crochet } s_{3} \text { at } t_{4}, I \text { sew } s_{3} \text { at } t_{4}\right\}\end{array}$ \\
\hline $\begin{array}{l}<\mathbf{s}_{4}, \mathbf{t}_{1}>: \\
<\mathbf{s}_{4}, \mathbf{t}_{2}>: \\
<\mathbf{s}_{4}, \mathbf{t}_{3}>: \\
<\mathbf{s}_{4}, \mathbf{t}_{4}>:\end{array}$ & $\begin{array}{l}\text { knit } s_{4} \text { at } t_{1}, I \text { crochet } s_{4} \text { at } t_{1}, I \text { sew } s_{4} \text { at } t_{1} \\
\text { knit } s_{4} \text { at } t_{2}, I \text { crochet } s_{4} \text { at } t_{2}, \text { I sew } s_{4} \text { at } t_{2} \\
\text { knit } s_{4} \text { at } t_{3}, I \text { crochet } s_{4} \text { at } t_{3}, I \text { sew } s_{4} \text { at } t_{3} \\
\text { knit } s_{4} \text { at } t_{4}, I \text { crochet } s_{4} \text { at } t_{4}, \text { I sew } s_{4} \text { at } t_{4}\end{array}$ \\
\hline
\end{tabular}

The second step is to check for each pair whether any of the alternatives are true. The result is shown in (24), with true alternatives in bold and underlined.

(24) Step 2:

\begin{tabular}{|c|c|}
\hline$\left\langle\mathbf{s}_{1}, \mathbf{t}_{1}\right\rangle:$ & $\left\{\underline{\mathbf{I} \text { knit } \underline{s}_{1}} \underline{\text { at } \mathbf{t}_{1}}, \underline{I}\right.$ crochet $\mathrm{s}_{1}$ at $\mathrm{t}_{1}, \mathrm{I}$ sew $\mathrm{s}_{1}$ at $\left.\mathrm{t}_{1}\right\}$ \\
\hline$<s_{1}, t_{2}>:$ & $\left\{\right.$ knit $s_{1}$ at $t_{2}, I$ crochet $s_{1}$ at $t_{2}, I$ sew $s_{1}$ at $\left.t_{2}\right\}$ \\
\hline$s_{4}, t_{3}>:$ & I Iknit $s_{4}$ at $t_{3}$, I erochet $s_{4}$ at $t_{3}$, Isew $s_{1}$ at $t_{3}+$ \\
\hline$<s_{1}, t_{4}>:$ & $\left\{\right.$ Iknit $s_{4}$ at $t_{4}$, I crochet $s_{4}$ at $t_{4}$, I sew $s_{4}$ at $\left.t_{4}\right\}$ \\
\hline$\left\langle\mathrm{s}_{2}, \mathrm{t}_{4}>:\right.$ & $\left\{\right.$ Iknit $s_{z}$ at $t_{4}, I$ crochet $s_{z}$ at $t_{4}, I$ \\
\hline$\left\langle\mathbf{s}_{2}, \mathbf{t}_{\mathbf{2}}\right\rangle:$ & $\left\{\underline{\mathbf{I ~ k n i t} \mathbf{s}_{2}}\right.$ at $\mathbf{t}_{2}$, I crochet $\mathrm{s}_{2}$ at $\mathrm{t}_{2}$, I sew $\mathrm{s}_{2}$ at $\left.\mathrm{t}_{2}\right\}$ \\
\hline$\left\langle\mathrm{s}_{2}, \mathrm{t}_{3}\right\rangle:$ & $\left\{\right.$ Iknit $s_{2}$ at $t_{3}$, I crochet $s_{2}$ at $t_{3}, I$ sew $s_{2}$ at $\left.t_{3}\right\}$ \\
\hline$\left\langle s_{2}, t_{4}>:\right.$ & $t_{4}$, I crochet $s_{2}$ at $t_{4}, I$ sew $s_{2}$ at $\left.t_{4}\right\}$ \\
\hline$<\mathrm{s}_{3}, \mathrm{t}_{1}>:$ & $\left\{\mathrm{kknit}_{3}\right.$ at $\mathrm{t}_{1}, \mathrm{I}$ erochet $\mathrm{s}_{3}$ at $\mathrm{t}_{1}, \mathrm{I}$ sew $\mathrm{s}_{3}$ at $\left.\mathrm{t}_{1}\right\}$ \\
\hline$<\mathrm{s}_{3}, \mathrm{t}_{2}>:$ & $\left\{\mathrm{kknit}_{3}\right.$ at $\mathrm{t}_{2}, \mathrm{I}$ crochet $\mathrm{s}_{3}$ at $\mathrm{t}_{2}, \mathrm{I}$ sew s $\mathrm{s}_{3}$ at $\left.\mathrm{t}_{2}\right\}$ \\
\hline$\left\langle\mathrm{s}_{3}, \mathrm{t}_{\mathbf{3}}\right\rangle:$ & $\left\{\underline{\mathbf{I} \text { knit } \mathbf{s}_{\mathbf{3}}} \underline{\text { at } \underline{\mathbf{t}}_{3}}\right.$, I crochet $\mathrm{s}_{3}$ at $\mathrm{t}_{3}, \mathrm{I}$ sew $\mathrm{s}_{3}$ at $\left.\mathrm{t}_{3}\right\}$ \\
\hline$<s_{3}, t_{4}>$ & ehet $s_{3}$ at $t_{4}, I$ sew $s_{3}$ at $t_{4}$ 子 \\
\hline$<s_{4}, t_{4}>:$ & $\left\{\right.$ Iknit $s_{4}$ at $t_{4}, I$ crochet $s_{4}$ at $t_{4}, I$ sew $s_{4}$ at $\left.t_{4}\right\}$ \\
\hline$\left\langle\mathrm{s}_{4}, \mathrm{t}_{2}\right\rangle$ & zet $s_{4}$ at $t_{2}, I$ sew $s_{4}$ att $\left.t_{2}\right\}$ \\
\hline$\left\langle s_{4}, t_{3}\right\rangle$ & et $\mathrm{s}_{4}$ at $t_{3}, \mathrm{I}$ sew $\mathrm{s}_{4}$ at $t_{3}$ \\
\hline$\left\langle\mathbf{s}_{\mathbf{4}}, \mathbf{t}_{\mathbf{4}}\right\rangle:$ & $\left\{\right.$ I knit $s_{4}$ at $t_{4}$, I crochet $s_{4}$ at $t_{4}$, I sew $\underline{s}_{4}$ at $\mathbf{t}_{4}$ \\
\hline
\end{tabular}

The pairs with no true alternatives are eliminated, leaving just the four pairs shown in (25).

(25) Result:

$$
\begin{aligned}
& \left\langle\mathbf{s}_{1}, \mathbf{t}_{1}\right\rangle: \quad\left\{\underline{\mathbf{I} \text { knit }} \mathbf{s}_{1} \text { at } \mathbf{t}_{1}, \text { I crochet } \mathrm{s}_{1} \text { at } \mathrm{t}_{1} \text {, I sew } \mathrm{s}_{1} \text { at } \mathrm{t}_{1}\right\} \\
& \left.\left\langle\mathbf{s}_{2}, \mathbf{t}_{\mathbf{2}}\right\rangle: \quad \quad \text { I knit } \mathbf{s}_{2} \text { at } \mathbf{t}_{2} \text {, I crochet } \mathrm{s}_{2} \text { at } \mathrm{t}_{2} \text {, I sew } \mathrm{s}_{2} \text { at } \mathrm{t}_{2}\right\} \\
& \left.\left\langle\mathbf{s}_{3}, t_{3}\right\rangle: \quad \quad \text { I knit } \mathbf{s}_{3} \text { at } \mathbf{t}_{3}, \text { I crochet } s_{3} \text { at } t_{3} \text {, I sew } s_{3} \text { at } t_{3}\right\} \\
& \left\langle\mathbf{s}_{4}, \mathbf{t}_{4}\right\rangle: \quad\left\{\text { I knit s}_{4} \text { at } \mathrm{t}_{4}, \text { I crochet } \mathrm{s}_{4} \text { at } \mathrm{t}_{4}, \underline{\mathbf{I} \text { sew } \mathbf{s}_{4}} \underline{a t}_{\mathbf{t}} \mathbf{t}_{4}\right\}
\end{aligned}
$$

It turns out that three out of four cases satisfy the quantification, so sentence (22) is correctly predicted to be true in the context given. Again, notice that if all 16 pairs were included in the domain, then only three out of 16 cases would satisfy the quantification and the sentence would be predicted to be false.

The reader can verify that this result generalizes to sentences with contrastive focus on other constituents such as the subject in (26) or the adverbial modifier in (27). 
(26) $[\mathrm{I}]_{\text {FOC }}$ usually knit a scarf.

$\approx$ when someone knits a scarf, I'm usually the one who does it.

(27) I usually knit a scarf [when it's RAINING $]_{\mathrm{FOC}}$.

$\approx$ when I knit a scarf, it's usually raining.

\section{Extending Focus Sensitivity}

I propose that in general, sentences with quantificational indefinites such as (28) are subject to a restriction parallel to the focus restriction, even when there is no narrow focus on the verb or another constituent.

$$
\begin{aligned}
& \text { I usually read a book about slugs. }[=(2)] \\
& \text { reading (ii) } \approx \text { When I encounter a book about slugs, I usually read it. }
\end{aligned}
$$

Informally speaking, what I propose is that a sentence like (28) is interpreted as if read were focused, but the alternatives to read were \{read, fail to read $\}$. This is formulated as a principle in (29). ${ }^{5}$

Principle of default focus: For the purposes of principle (18), if a sentence $S$ has no overt contrastive focus, it's taken to have the alternative set $\{\mathrm{S}$, FAIL-To $S\}$, where FAIL-TO $\mathrm{p}=$ NOT $\mathrm{p}$ and POSSIBLE $\mathrm{p}=\sim \mathrm{p} \& \diamond \mathrm{p}$

This principle involves an operator "FAIL-To," which is essentially negation plus a possibility modal. The modality involved is something like opportunity. Using Kratzer's semantics for modals (Kratzer 1977, 1991), this means that the modal base is restricted to worlds where all the facts up to the specified point in time are the same as in the actual world. Requirements of a deontic or other nature also need to be included so that, for example, seeing a book about slugs in the window of a closed bookstore doesn't count as an opportunity to read it, even if it would be possible to get the book by smashing the window. Formally, though, FAIL-To just includes propositional negation and a possibility modal.

Now we can see how the principle of default focus in (29) works, using (28) as an example. As before, let's assume for simplicity that there are just four relevant books about slugs, $b_{1}$, $b_{2}, b_{3}$, and $b_{4}$, and four relevant times, $t_{1}, t_{2}, t_{3}$, and $t_{4}$. Now suppose that $I$ had the opportunity to read $b_{1}$ at $t_{1}, b_{2}$ at $t_{2}, b_{3}$ at $t_{3}$, and $b_{4}$ at $t_{4}$. I actually read $b_{1}$ at $t_{1}, b_{2}$ at $t_{2}$, and $b_{3}$ at $t_{3}$, and $I$ didn't read or have the opportunity to read any other relevant books at relevant times. We can construct the domain of quantification as before, except that the alternatives are generated by the principle of default focus in (29). The first step is to list all the possible pairs of books and times, with their alternatives, as shown in (30).

(30) Step 1:

$$
\begin{aligned}
& \left\langle\mathbf{b}_{1}, \mathbf{t}_{1}\right\rangle: \quad\left\{\text { I read } b_{1} \text { at } t_{1}, \text { I FAIL-To read } b_{1} \text { at } t_{1}\right\} \\
& \left\langle\mathbf{b}_{1}, \mathbf{t}_{2}\right\rangle: \quad\left\{\text { I read } b_{1} \text { at } t_{2} \text {, I FAIL-To read } b_{1} \text { at } t_{2}\right\} \\
& \left.\left\langle\mathbf{b}_{1}, \mathbf{t}_{3}\right\rangle: \quad \quad \text { I read } b_{1} \text { at } t_{3} \text {, I FAIL-To read } b_{1} \text { at } t_{3}\right\} \\
& \left\langle\mathbf{b}_{1}, \mathbf{t}_{4}\right\rangle: \quad\left\{\text { I read } b_{1} \text { at } t_{4} \text {, I FAIL-To read } b_{1} \text { at } t_{4}\right\} \\
& \left\langle\mathbf{b}_{2}, \mathbf{t}_{\mathbf{1}}\right\rangle: \quad\left\{\mathrm{I} \mathrm{read} \mathrm{b}_{2} \text { at } \mathrm{t}_{1} \text {, I FAIL-To read } \mathrm{b}_{2} \text { at } \mathrm{t}_{1}\right\} \\
& \left.\left\langle\mathbf{b}_{2}, \mathbf{t}_{\mathbf{2}}\right\rangle: \quad \quad \text { I read } \mathrm{b}_{2} \text { at } \mathrm{t}_{2} \text {, I FAIL-To read } \mathrm{b}_{2} \text { at } \mathrm{t}_{2}\right\} \\
& \left\langle\mathbf{b}_{2}, \mathbf{t}_{3}\right\rangle: \quad\left\{\text { I read } b_{2} \text { at } t_{3} \text {, I FAIL-To read } b_{2} \text { at } t_{3}\right\} \\
& \left.\left\langle\mathbf{b}_{\mathbf{2}}, \mathbf{t}_{\mathbf{4}}\right\rangle: \quad \quad \text { I read } \mathrm{b}_{2} \text { at } \mathrm{t}_{4} \text {, I FAIL-To read } \mathrm{b}_{2} \text { at } \mathrm{t}_{4}\right\}
\end{aligned}
$$

\footnotetext{
${ }^{5}$ Principle (29) is reminiscent of Johnston's (1994) idea that for a case to count in quantification, it must be "a fair question" whether the nuclear scope holds of that case. (29) could also be seen as a modification of Ahn's (2005) idea that the minimal restriction of a quantifier consists of the disjunction of the "polar alternatives" of the nuclear scope.
} 


\begin{tabular}{|c|c|}
\hline $\begin{array}{l}\left\langle\mathbf{b}_{3}, \mathbf{t}_{1}\right\rangle: \\
\left\langle\mathbf{b}_{3}, \mathbf{t}_{2}\right\rangle: \\
\left\langle\mathbf{b}_{3}, \mathbf{t}_{3}\right\rangle: \\
\left\langle\mathbf{b}_{3}, \mathbf{t}_{4}\right\rangle:\end{array}$ & $\begin{array}{l}\left\{\text { I read } b_{3} \text { at } t_{1}, \text { I FAIL-To read } b_{3} \text { at } t_{1}\right. \\
\left\{\text { I read } b_{3} \text { at } t_{2}, \text { I FAIL-To read } b_{3} \text { at } t_{2}\right. \\
\left\{\text { I read } b_{3} \text { at } t_{3}, \text { I FAIL-To read } b_{3} \text { at } t_{3}\right. \\
\left\{\text { I read } b_{3} \text { at } t_{4}, \text { I FAIL-To read } b_{3} \text { at } t_{4}\right.\end{array}$ \\
\hline${ }_{4}, t_{2}>:$ & $\begin{array}{l}\text { read } b_{4} \text { at } t_{2} \text {, I FAIL-To read } b_{4} \text { at } \\
\text { read } b_{4} \text { at } t_{3} \text {, I FAIL-To read } b_{4} \text { at } \\
\text { read } b_{4} \text { at } t_{4} \text {, I FAIL-To read } b_{4} \text { at }\end{array}$ \\
\hline
\end{tabular}

The second step, checking each pair for true alternatives, is shown in (31).

(31) Step 2:

\begin{tabular}{|c|c|}
\hline $\begin{array}{l}\left\langle\mathrm{b}_{1}, \mathrm{t}_{1}\right\rangle: \\
\left\langle\mathrm{b}_{1}, \mathbf{t}_{2}>:\right. \\
\left\langle\mathrm{b}_{1}, \mathrm{t}_{3}>:\right. \\
<\mathrm{b}_{4}, \mathrm{t}_{4}>:\end{array}$ & 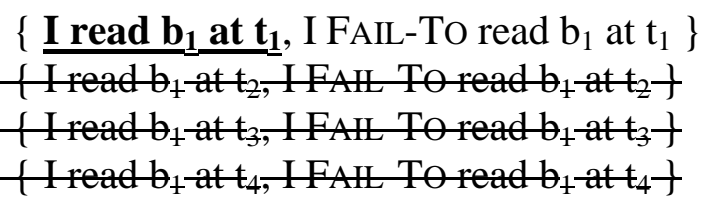 \\
\hline $\begin{array}{l}\left\langle b_{2}, t_{1}\right\rangle: \\
\left\langle b_{2}, t_{2}\right\rangle: \\
\left\langle b_{2}, t_{3}>:\right. \\
\left\langle b_{2}, t_{4}>:\right.\end{array}$ & 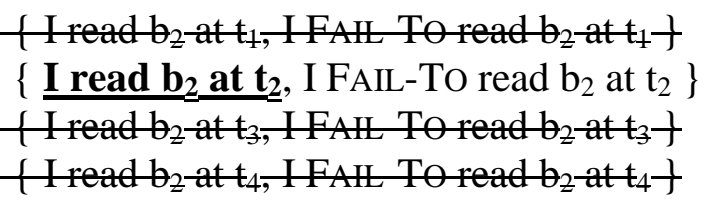 \\
\hline $\begin{array}{l}\left\langle b_{3}, t_{1}>:\right. \\
\left\langle b_{3}, t_{2}\right\rangle: \\
\left\langle b_{3}, t_{3}\right\rangle: \\
\left\langle b_{3}, t_{4}>:\right.\end{array}$ & 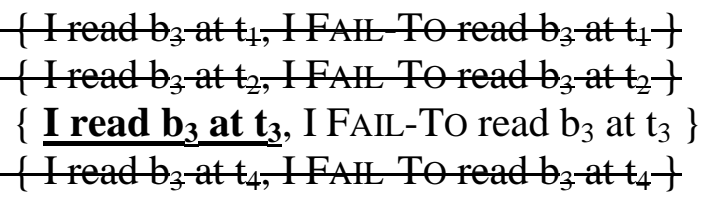 \\
\hline $\begin{array}{l}\left\langle\mathrm{b}_{4}, \mathbf{t}_{1}\right\rangle: \\
\left\langle\mathrm{b}_{4}, \mathbf{t}_{2}>:\right. \\
\left\langle\mathrm{b}_{4}, \mathbf{t}_{3}>:\right. \\
\left.<\mathbf{b}_{4}, \mathbf{t}_{4}\right\rangle:\end{array}$ & $\begin{array}{l}\left\{\text { Iread } b_{4} \text { at } t_{1}, \text { IFAIL To read } b_{4} \text { at } t_{1}\right\} \\
\left\{\text { I read } b_{4} \text { at } t_{2}, \text { IFAIL To read } b_{4} \text { at } t_{2}\right\} \\
\left\{\text { I read } b_{4} \text { at } t_{3}, \text { IFAIL To read } b_{4} \text { at } t_{3}\right\} \\
\left\{\text { I read } b_{4} \text { at } t_{4}, \underline{I} \text { FAIL-To read } \mathbf{b}_{4} \text { at } \mathbf{t}_{4}\right\}\end{array}$ \\
\hline
\end{tabular}

The resulting domain is just the four pairs shown in (32).

(32) Result:

$$
\begin{aligned}
& \left\langle\mathbf{b}_{1}, \mathbf{t}_{1}\right\rangle: \quad\left\{\underline{\mathbf{I r e a d} \mathbf{b}_{1}} \text { at } \mathbf{t}_{1}, \quad \text { I FAIL-To read } \mathrm{b}_{1} \text { at } \mathrm{t}_{1}\right\} \\
& \left.\left\langle\mathbf{b}_{2}, \mathbf{t}_{\mathbf{2}}\right\rangle: \quad \quad \text { I read } \mathbf{b}_{2} \text { at } \mathbf{t}_{2}, \text { I FAIL-TO read } \mathrm{b}_{2} \text { at } \mathrm{t}_{2}\right\} \\
& \left.\left\langle\mathbf{b}_{3}, \mathbf{t}_{3}\right\rangle: \quad \quad \text { I read } \mathbf{b}_{3} \text { at } \mathbf{t}_{3}, \text { I FAIL-To read } b_{3} \text { at } t_{3}\right\} \\
& \left.\left\langle\mathbf{b}_{\mathbf{4}}, \mathbf{t}_{\mathbf{4}}\right\rangle: \quad \quad \quad \mathrm{I} \mathrm{read} \mathrm{b}_{4} \text { at } \mathrm{t}_{4} \text {, I FAIL-To read } \mathbf{b}_{4} \text { at }_{\mathbf{4}}\right\}
\end{aligned}
$$

As with the previous example, three out of these four pairs satisfy the quantification, so (28) is correctly predicted to be true in the context given. Once again, if all 16 pairs were included, the sentence would incorrectly be predicted to be false.

More generally, when the principles of focus restriction (18) and default focus (29) are added to the assumptions from Section 3, sentence (28) is predicted to have the meaning shown in (33) below. Note that in (33), $\mathrm{T}^{*}$ is the entire relevant interval of time, and FR is standing in for the focus restriction (that is, in this case it stands for the set of pairs $\langle x, t\rangle$ such that I had the opportunity to read $x$ at $t$ ).

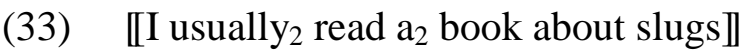

$$
=\llbracket(28) \rrbracket
$$

$=\llbracket$ usually $2 \rrbracket^{\mathrm{T}^{*}}\left(\llbracket \mathrm{a}_{2}\right.$ book about slugs $\left.\rrbracket \cap \mathbf{F R}\right)\left(\llbracket \operatorname{PERF}\left[\operatorname{Iread}\left(\_\right)\right] \rrbracket\right)$

$=1$ iff for most $\langle\mathrm{x}, \mathrm{t}\rangle$ such that $\mathrm{x}$ is a book about slugs (at some $\mathrm{t}^{\prime}$ ), $\mathrm{t} \subseteq$ int $\mathrm{T}$, and $t$ is a maximal interval at which $I$ have the opportunity to read $x$,

I read $\mathrm{x}$ at some subinterval of $\mathrm{t}$. 
Note that this is no longer equivalent to quantifying over books because the maximal intervals of opportunity can, and normally will, be smaller than $\mathrm{T}$.

Informally, then, the relevant reading of (28) can be paraphrased as, "Usually, when I have the opportunity to read a particular book about slugs, I read it." Recall that the paraphrase given to it earlier was, "Usually, when I encounter a book about slugs, I read it." This makes sense given that the opportunity to read a book normally involves encountering it somehow.

Similarly, my proposal predicts that sentence (1), I usually love a sonata by Dittersdorf, can be paraphrased as, "Usually, when I have the opportunity to love a sonata by Dittersdorf, I love it." The paraphrase given earlier was, "Usually, when I hear a sonata by Dittersdorf, I love it." This again makes sense because loving a sonata normally requires hearing it. Parallel predictions are made for other examples with quantificational indefinites.

\section{Predictions of the Analysis}

In this section, I'll show how my proposal accounts for the two crucial contrasts discussed at the beginning, between creation and non-creation verbs on the one hand, and between focused and unfocused creation verbs on the other.

\subsection{Creation verbs vs. non-creation verbs}

Recall that a quantificational reading of an indefinite is not available in sentences like (34).

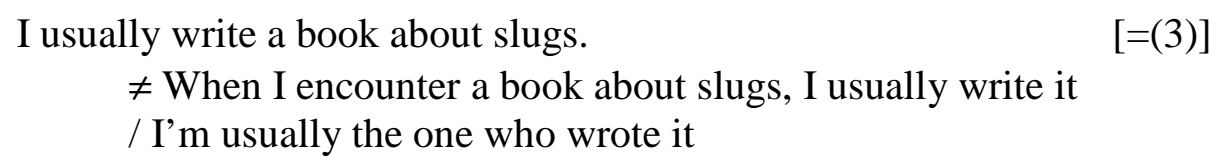

I usually write a book about slugs. $[=(3)]$ $\neq$ When I encounter a book about slugs, I usually write it / I'm usually the one who wrote it

To see how my proposal accounts for this fact, consider what would have to be the case for a particular pair $\langle\mathrm{x}, \mathrm{t}\rangle$ to be included in the domain of quantification for usually. First, $\mathrm{x}$ must be a book about slugs. Second, $t$ must be a time at which I had the opportunity to write $\mathrm{x}$. But consider this: for any interval in the actual world when a person has the time, resources, and so on to write a book about slugs (that is, some book or other), there will normally be many different compatible worlds where they write a book as a result of this opportunity. These possible books might be very different from each other: they could include different facts or events, be different lengths, have different writing styles, and so on. So in order to have the opportunity to write a particular book, it needs to be possible to individuate that book out of this vast class of possible alternative books. Put another way, there needs to be a way to tell which different possible books should be thought of as the same book, and which ones should be thought of as different books. There's no reason to believe that the context will generally provide this, however, and I suggest that in most cases it doesn't. When this happens, it will simply not be possible to resolve the domain of quantification, and so the relevant reading of the sentence will not be available. In other words, a quantificational reading is unavailable for the indefinite in (34) because the example doesn't give enough contextual information to individuate the relevant possible books.

\subsection{The freelance writer context}

I've argued that the reason quantificational indefinites are not generally possible with creation verbs is that context doesn't generally provide enough information to individuate possible books. By the same token, though, if we could set up a context where the relevant books that someone had the opportunity to write were sufficiently individuated, then a quantificational reading should be possible with a creation verb such as write. This prediction is borne out, as seen by (35). Similar examples can be constructed with other verbs of creation. 
(35) [Context: I'm a freelance writer who gets requests from clients to write books, articles, and so on to various specifications.]

I usually write a book about slugs. $=$ When I get a request for a book about slugs, I usually take the job.

In this case, it's clear that when I get a request to write a book, that counts as an opportunity to write a specific book. That is, possible books from different worlds count as the same book just in case they were written in response to the same request.

Notice that if we adopted Diesing's view using a preexistence requirement (putting aside its problems for a moment), the only way to explain examples like (35) would be to say that in such contexts, books can count as "existing" for the purposes of the preexistence requirement before they're actually written. This may or may not be a problem depending on how one's theory deals with the host of issues relating to existence, incomplete objects, and possible individuals in general. ${ }^{6}$ However, it should be noted that my proposal accounts for examples like (35) in a way that is independent of any particular view of these issues.

\subsection{Focused vs. unfocused creation verbs}

Recall that when a creation verb is focused as in (36), the natural reading is parallel to other examples of quantificational indefinites.

(36) I usually $[\mathrm{KNIT}]_{\mathrm{FOC}}$ a scarf. $=$ When I make a scarf, I usually do it by knitting.

$$
[=(4 . b)]
$$

An account like Diesing's, using a preexistence requirement, incorrectly predicts that this reading should be unavailable. My proposal, on the other hand, straightforwardly accounts for sentences like (36) because in this case, a set of salient alternatives to the focused item must be available - for example, $\{\mathrm{knit}$, crochet, sew $\}$. This means that the normal focus restriction (18) applies without the default focus principle (29), so the problem of determining what counts as an opportunity to knit a particular scarf doesn't arise.

\section{Conclusions}

My proposal about quantificational indefinites has two main ingredients. The first ingredient is the idea that quantification is restricted by focus alternatives, adopted from work by Rooth, von Fintel, and others and set forth as principle (18). The second ingredient is the principle of default focus in (29), which provides sets of default alternatives of the form $\{p$, FAIL-To $p\}$ to sentences with quantificational indefinites. Once these default alternatives are present, the focus restriction can apply in the normal way. Since FAIL-To has a modal component, the result is that quantificational indefinites come with a certain kind of modal restriction, which seems to capture the intuitive truth conditions of the relevant sentences.

Besides giving a plausible semantics for quantificational indefinites, this proposal explains why they behave differently with creation verbs than with non-creation verbs. I assume that in these sentences, the objects being quantified over are pairs $\langle x, t\rangle$ of individuals and times. The crucial restriction involves modality, which makes it necessary to determine how to identify individuals across worlds, and it's typically difficult to do this in contexts involving creation verbs. Therefore quantificational readings of indefinites are normally impossible with creation verbs. On the other hand, there are some contexts involving creation verbs that do include enough information about how to identify individuals across worlds, in which case a quantificational reading is possible.

\footnotetext{
${ }^{6}$ For some recent discussion, see, e.g., von Stechow (2001).
} 
Finally, my proposal explains why quantificational readings of indefinites are possible when the verb is focused, regardless of whether or not it's a creation verb. This is because the verb has focus alternatives of its own, so the default alternatives of the form $\{p$, FAIL-To $p\}$ are never generated. This takes away the modal component and the resultant problem of identifying individuals across worlds.

\section{References}

Ahn, D. D., 2005. Presupposition incorporation in adverbial quantifier domains. In E. Maier, C. Bary, and J. Huitink (eds.), Proceedings of SuB9, pp. 16-29, www.ru.nl/ncs/sub9.

Diesing, M., 1992. Indefinites. Linguistic Inquiry Monograph 20. Cambridge, Massachusetts: MIT Press.

von Fintel, K., 1994. Restrictions on Quantifier Domains. Ph.D. dissertation, University of Massachusetts, Amherst. GLSA Publications.

Johnston, M., 1994. The Syntax and Semantics of Adverbial Adjuncts. Ph.D. dissertation, University of California, Santa Cruz.

Kratzer, A., 1977. What 'must' and 'can' must and can mean. Linguistics and Philosophy 1, 337-355.

Kratzer, A., 1991. 'Modality'/ 'Conditionals.' In A. von Stechow and D. Wunderlich (eds.), Semantik. Ein internationales Handbuch der zeitgenössischen Forschung, de Gruyter, pp. 639-659.

Landman, F., 1992. The progressive. Natural Language Semantics 1, 1-32.

Lewis, D., 1975. Adverbs of quantification. In E. L. Keenan (ed.), Formal Semantics of Natural Language, Cambridge University Press, pp. 3-15.

Parsons, T., 1990. Events in the Semantics of English: A Study in Subatomic Semantics. Cambridge, Massachusetts: MIT Press.

Percus, O., 1999. A more definite article. Quaderni del Dipartimento di Linguistica, 2001, University of Florence.

Portner, P., 1998. The progressive in modal semantics. Language 74, 760-787.

Rooth, M. E., 1985. Association with Focus. Ph.D. dissertation, University of Massachusetts, Amherst. GLSA Publications.

von Stechow, A., 2001. Temporally opaque arguments in verbs of creation. In C. Cecchetto, G. Chierchia, and T. Guasti (eds.), Semantic Interfaces: Reference, Anaphora, and Aspect, CSLI, pp. 278-319. 